\title{
Early Diagnosis of Gynecological Cancers in Ladies with Review of Literature
}

\author{
Tanushri Mukherjee ${ }^{1}$, Soma Mukherjee², Rajat Dutta ${ }^{3}$ \\ ${ }^{1}$ Department of Pathology, Command Hospital Chandimandir, Chandigarh, India \\ ${ }^{2}$ Department of Obstetrics \& Gynaecology, AIIMS, Bhopal, India \\ ${ }^{3}$ Department of Surgery, Command Hospital, Kolkata, India \\ Email: tanujamukherjee@yahoo.com
}

How to cite this paper: Mukherjee, $\mathrm{T}$., Mukherjee, S. and Dutta, R. (2017) Early Diagnosis of Gynecological Cancers in Ladies with Review of Literature. Open Journal of Obstetrics and Gynecology, 7, 520524

https://doi.org/10.4236/ojog.2017.75054

Received: April 16, 2017

Accepted: May 20, 2017

Published: May 23, 2017

Copyright $\odot 2017$ by authors and Scientific Research Publishing Inc. This work is licensed under the Creative Commons Attribution International License (CC BY 4.0).

http://creativecommons.org/licenses/by/4.0/

\section{Abstract}

The most prevalent cancers in ladies are cervical, endometrial and Ovarian. The biomarkers prevalent in use for these gynaecological cancers are commonly Cancer antigen 125 (CA-125), B, Alpha-fetoprotein (AFP), Inhibin, Carcinoembryonic antigen (CEA), Squamous cell carcinoma (SCC) antigen, Carbohydrate antigen 19-9, Cancer antigen 27-29, Human epididymis protein 4 (HE4), Osteopontin, transthyretin, Immunosuppressive acidic protein(IAP), leptin, CA15-3, CK19 and Thymidine kinase. The biomarker marker Squamous cell carcinoma (SCC) antigen, CK19 and immunosuppressive acidic protein IAP are raised in cervical squamous cell carcinomas. Endometrial cancer is a common cancer in women. In $75 \%$ of endometrial cancer cases, the tumor remains confined to the uterus and has a favorable prognosis if early detected. The prognosis, however, worsens dramatically as the disease progresses. The objective of this review is to elucidate the importance of the tumor markers for early diagnosis of gynaecological malignancies which are vital and life saving. Similarly the relevant biomarkers in combination are found to have positive predictive values and significant $\mathrm{p}$ values in the endometrial and cervical cancer. In Cervix cancer the positive predictive value of these markers combined is usually $92 \%$ - 95\% and negative predictive value $93 \%-96 \%$. The confidence interval is $98 \%$ and p value significant 0.005 . Sensitivity of tumor markers combined CK19, SCC and immunosuppressive acidic protein IAP in Cervix cancer detection is $95 \%$ and specificity $96 \%$. The highest sensitivity was for SCC antigen (98.7\%) while the highest specificity was for Cytokeratin 19 (99.7\%). The positive predictive value by combination of CK19, SCC and IAP for the detection of Cervix cancer was $90 \%$ - 94\%. In endometrial cancer the sensitivity of tumor markers combined CA19-9, CA125, leptin, thymidine kinase, CEA, CA15-3, and HE4 in endometrial cancer detection was $95 \%$ and specificity $96 \%$. The highest sensitivity was for CA125 (99.7\%) while the highest specificity was for CA19-9 (95.7\%) which revealed that the efficacy of 
CA19-9 was more than that of CA125. The positive predictive value by combination of CA19-9, CA-125 levels, HE4, CA15-3, leptin, thymidine kinase and CEA for the detection of Endometrial cancer was 93\%. For Gynecological malignancies namely Ovarian, Cervix and Endometrial cancers screening with these novel tumor markers in combination which are significant to a particular group of cancers.

\section{Keywords}

Gynaecological Cancers, Tumor Markers

\section{Introduction}

The study of biomarkers is in vogue in gynecological cancers namely ovarian serous epithelial cancers, endometrial and cervical cancers. The Ovarian epithelial tumors comprise $60 \%$ of ovarian neoplasms and more than $90 \%$ of malignant tumors of the ovary [1]. In Serous epithelial carcinomas the biomarkers are used for detection, follow up and prognosis and the role of biomarkers is not established in other Ovarian Cancers like Mucinous or endometrioid cancers. Endometrial Carcinoma is around 7\% of all invasive cancers in women. The cervix cancers are of various types like squamous, adenocarcinoma, neuroendocrine carcinomas etc. The biomarkers which are found to be useful in these malignancies are that which are detected in the body fluids and tissues of cancer patient and these can be hormones, oncofetal antigens, enzymes and receptors. The biomarkers prevalent in use for these three gynaecological cancers are commonly Cancer antigen 125 (CA-125), B, Alpha-fetoprotein (AFP), Inhibin, Carcinoembryonic antigen (CEA), Squamous cell carcinoma (SCC) antigen, Carbohydrate antigen 19-9, Cancer antigen 27 - 29, Human epididymis protein 4 (HE4), Osteopontin, transthyretin, Immunosuppressive acidic protein, leptin, CA15-3, CK19 and Thymidine kinase and the exact importance is not elucidated properly so as to establish them as a proper screening and prognostic tool.

The biomarker marker Squamous cell carcinoma (SCC) antigen is raised in cervical squamous cell carcinomas. Endometrial cancer is a common cancer in women. In $75 \%$ of endometrial cancer cases, the tumor remains confined to the uterus and has a favorable prognosis if early detected. The prognosis, however, worsens dramatically as the disease progresses. Thus early diagnosis of these gynaecological malignancies is vital and life saving. The biomarkers help in the early diagnosis, screening, treatment, response, follow up and prognosis.

\section{Discussion}

The review of literature was done simply on the basis of significant study of tumor markers in various gynaecological cancers. In Ovarian Cancer, the positive predictive value of CA125 assay to be $57 \%$ whereas in contemporary studies the positive predictive value of CA125 was 50\% - 92\%, CA19-9 68\% - 83\%, CA15-3 
$50 \%-56 \%$ and Immunosuppressive acidic protein 70\% - 93\%. HE4 had significantly higher concentrations in Ovarian serous cancer $(p<0.001)$. Tumour marker sensitivity in ovarian cancer was $79.3 \%$ for HE4, 82.9\% for CA 125 [1].

In advanced epithelial ovarian cancer Kang et al. [2] studied the CA125 levels in 153 patients and found better the survival of 32.4 months in when CA-125 values were less than $10 \mathrm{U} / \mathrm{ml}$ and the survival was 16.8 months in those patients with Ovarian Cancer with CA 125 levels of $0-35 \mathrm{U} / \mathrm{mL}(p=0.0001)$.

In the study of biomarkers in Ovarian Cancer Van Gorp et al. [3] found the mean CA125 value of $324.98 \pm 98$ for malignant ovarian tumors in comparison to low values in benign ovarian tumors and they found significant statistical significance between the benign and malignant tumors $(p=0.5)$. Anton et al. [4] studied the biomarkers HE4 and CA125 in 491 patients and found sensitivity of $73 \%$ and $88 \%$ respectively, and the results were significant. Moore et al. [5] studied HE4 in Ovarian cancer and found sensitivity to be $94.9 \%$ at a $95 \%$ specificity $(p=0.50)$. The positive predictive value by combination of CA-125 levels, HE4, CA19-9 and CEA for the detection of Ovarian cancer was 94\%. Zhang et al. [6] also studied the biomarkers CA19-9, CA15-3 and their statistical correlation was not significant in Ovarian Cancer and did not corresponded with the clinical course of the disease. Vistintin et al. [7] found the levels of leptin, prolactin, osteopontin to be $95 \%$ sensitive and $99 \%$ specific in Ovarian cancer.

In cervix cancer Scambia et al. [8] studied serum levels of squamous cell carcinoma antigen (SCC), CA 125 and CA 15.3 in 102 patients with locally advanced cervical cancer undergoing neoadjuvant chemotherapy (NACT) and radical surgery. They found a significant correlation between SCC concentration and stage, histotype, cervical tumour size and lymph node status. For CA 125 and CA 15.3, no significant difference in the distribution of marker levels according to histopathological variables was found. In a multivariate analysis, histological type, FIGO stage and SCC positivity $(>5 \mathrm{ng} / \mathrm{ml}$ ) proved to be independent predictors of response to neoadjuvant chemotherapy. Moreover, logistic regression analysis showed that CA 15.3 may be a significant adjunct to SCC in the prediction of chemotherapy response. Of the three markers tested, only CA 125 was significantly related to patient survival. In the multivariate analysis, clinical response to chemotherapy and CA 125 status $(>35 \mathrm{U} / \mathrm{ml})$ retained an independent prognostic value. Pretreatment serum levels of SCC, together with CA 15.3 assay, may be a useful tool in the determination of response to chemotherapy, while CA 125 assay could be evaluated as a prognostic risk factor in these patients.

Ginath et al. studied [9] 39 patients found that $21.4 \%$ of 28 patients with endometrioid endometrial carcinoma had elevated serum CA 125 and there was correlation with the stage of the tumor. Kurihara et al. [10] found in their study that serum CA 125 had a sensitivity of $69.0 \%$, specificity of $74.1 \%$, positive predictive value of $58.8 \%$ and negative predictive value of $81.6 \%$. Takami et al. [11] studied the rerlevant biomarkers in endometrial cancers and found high CA 125 levels in endometrial cancer in 291 patients and the result was statistically sig- 
nificant. The levels of CA125 in the ranged from 2.1 to $43.0 \mathrm{U} / \mathrm{ml}(17.2 \pm 2.3$ $\mathrm{U} / \mathrm{ml}$ ) and the difference of the mean value of the two groups was statistically significant $(p<0.001)$. The CA125 levels in correlation was seen $($ CA125 $=0.6 \times$ age $+11.5, p<0.05)$. Patients with endometrial cancer showed a decrease in their CA125 levels after a hysterectomy and salpingo-oophorectomy $(6.5 \pm 1.2$ $\mathrm{U} / \mathrm{ml}, p<0.0001)$.

\section{Conclusion}

For Gynecological malignancies namely Ovarian, Cervix and Endometrial cancers screening with these novel tumor markers in combination which are significant to a particular group of cancers. The tumor markers namely CA125, HE4, CA19-9, CEA and CA15-3 can be used for screening in suspected ovarian cancers, SCC antigen, CK19 and IAP for screening in suspected cervix cancer patients and CA125, CA19-9, CEA, CA15-3 and HE4 for screening in endometrial cancer.

\section{References}

[1] Molina, R., Jose, M., Escudera, et al. (2011) HE4 a Novel Tumour Marker for Ovarian Cancer: Comparison with CA 125 and ROMA Algorithm in Patients with Gynaecological Diseases. Tumor Biology, 32, 1087-1095. https://doi.org/10.1007/s13277-011-0204-3

[2] Kang, W.D., Choi, H.S. and Kim, S.M. (2010) Value of Serum CA125 Levels in Patients with High-Risk, Early Stage Epithelial Ovarian Cancer. Gynecologic Oncolo$g y, 116,57-60$.

[3] Van Gorp, T., Cadron, I., Despierre, E., Daemen, A., Leunen, K., et al. (2011) HE4 and CA125 as a Diagnostic Test in Ovarian Cancer: Prospective Validation of the Risk of Ovarian Malignancy Algorithm. British Journal of Cancer, 104, 863-870. https://doi.org/10.1038/sj.bjc.6606092

[4] Anton, C., Filomina, M., Carvalho, et al. (2012) A Comparison of CA125, HE4, Risk Ovarian Malignancy Algorithm (ROMA), and Risk Malignancy Index (RMI) for the Classification of Ovarian Masses. Clinics, 67, 437-441.

[5] Moore, R.G., Jabre-Raughley, M., Brown, A.K., Robison, K.M., Miller, M.C., Allard, W.J., Kurman, R.J., Bast, R.C. and Skates, S.J. (2010) Comparison of a Novel Multiple Marker Assay vs. the Risk of Malignancy Index for the Prediction of Epithelial Ovarian Cancer in Patients with a Pelvic Mass. American Journal of Obstetrics \& Gynecology, 228-232.

[6] Zhang, Z., Bast, R.C., Yu, Y., Li, J., Sokoll, L.J., Rai, A.J., et al. (2004) Three Biomarkers Identified from Serum Proteomic Analysis for the Detection of Early Stage Ovarian Cancer. Cancer, 43, 123-125. https://doi.org/10.1158/0008-5472.can-04-0746

[7] Visintin, M., Sakuragi, N., Okamoto, K., Todo, Y., et al. (2002) Preoperative Serum SCC, CA125, and CA19-9 Levels and Lymph Node Status in Squamous Cell Carcinoma of the Uterine Cervix. Acta Obstetricia et Gynecologica Scandinavica, 81, 451-457. https://doi.org/10.1034/j.1600-0412.2002.810513.x

[8] Scambia, G., Benedetti, P., Foti, E., Ferrandina, G., Leone, F.P., Marciano, M. and Mancuso, S. (1996) Multiple Tumor Marker Assays in Advanced Cervical Cancer: Relationship to Chemotherapy Response and Clinical Outcome. European Journal of Cancer, 32A, 259-263. 
[9] Ginath, S., Menczer, J., Fintsi, et al. (2002) Tissue and Serum CA125 Expression in Endometrial Cancer. International Journal of Gynecological Cancer, 12, 372-375. https://doi.org/10.1046/j.1525-1438.2002.01007.x

[10] Kurihara, T., Mizunuma, H., Obara, M., Andoh, K., Ibuki, Y., et al. (1998) Determination of a Normal Level of Serum CA 125 in Postmenopausal Women as a Tool for Preoperative Evaluation and Postoperative Surveillance of Endometrial Carcinoma. Gynecologic Oncology, 69, 192-196. https://doi.org/10.1006/gyno.1998.5018

[11] Takami, M., Sakamoto, H., Ohtani, K., Takami, T., et al. (1997) An Evaluation of CA125 Levels in 291 Normal Postmenopausal and 20 Endometrial Adenocarcinoma-Bearing Women before and after Surgery. Cancer Letters, 16, 69-72.

\section{Abbreviation List}

Cancer antigen 125 (CA-125),

B, Alpha-fetoprotein (AFP),

Carcinoembryonic antigen (CEA),

Squamous cell carcinoma (SCC) antigen,

Carbohydrate antigen 19-9 (CA19-9),

Cancer antigen 125 (CA125),

Human epididymis protein 4 (HE4).

\section{Scientific Research Publishing}

Submit or recommend next manuscript to SCIRP and we will provide best service for you:

Accepting pre-submission inquiries through Email, Facebook, LinkedIn, Twitter, etc. A wide selection of journals (inclusive of 9 subjects, more than 200 journals) Providing 24-hour high-quality service User-friendly online submission system Fair and swift peer-review system Efficient typesetting and proofreading procedure Display of the result of downloads and visits, as well as the number of cited articles Maximum dissemination of your research work

Submit your manuscript at: http://papersubmission.scirp.org/ Or contact ojog@scirp.org 